\title{
LANGUAGE AND SIGNS \\ In Heidegger's What Is Called Thinking
}

JON STUART VICTOR

"We are a sign that is not read."-Hölderlin

$\mathrm{O}$ analyze the ways in which humans relate to Being is to examine the extent to
which they are alone in the world. The death of God, announced by Friedrich Nietzsche in Aphorism 125 of "The Gay Science," threatened the loss of Being forever, a loss that Martin Heidegger acutely felt as he strove to reframe humanity's relation to the metaphysical. ${ }^{1}$ The task, at times, feels gloomy. For if a human being is a sign — as Heidegger states - he exists only in relation to something else, something that, Friedrich Hölderlin says, does not even read the sign. For as we turn to meet Being in all its glory and completeness, we find that Being has withdrawn from us. We are left alone. "We are a sign that is not read."

Heidegger introduces this line from Hölderlin early in his text, What is Called Thinking? He lets it stand before the reader, moving on to discuss the nature of the poetic word, rather than explaining its philosophical utility. One is, indeed, left with questions. Why are we not read? What could read us in the first place? I believe that Heidegger says that we are a sign that is not read in order to highlight precisely the extent to which Being has withdrawn from us, forming an analogy between the linguistic sign and our pointing toward Being. Whereas the linguistic sign's referent meets it where it lies, Being has turned away from humanity, leaving it to point

1 Nietzsche, Friedrich. "The Gay Science, translated by Walter Kaufmann." New York: Vintage 374 (1974): 181. 
aimlessly into oblivion, as a sign without significance - a sign that is not read. In the same sense that we cannot think until we know what it is that calls us to thought (or so Heidegger says), we cannot be a sign that is read until we can access the sign's signifier - the thing it points to. In this case, what we are pointing to has turned away from us long ago.

While Heidegger explores several modalities of Being, such as thinking, memory and traveling, as part of his discussion on human being, perhaps no modality is as illuminative of what a human being is as his comparisons of humans to language. The philosopher's conception of the human being as a sign establishes a relationship between humans and Being that he says must always be present, even if the withdrawal of one side threatens how each interacts with the other. Heidegger writes, "man is the being who is in that he points toward 'Being,' and who can be himself only as he always and everywhere refers himself to what is." ${ }^{2}$ The relationship between humanity and Being is one of essence, but the essence is signification, which, in turn, implies separation. Humans, as beings, are necessarily separate from Being insofar as they must constantly be referring themselves to it in order to partake in its essence. As a linguistic sign has no meaning (except that which it receives from the real-world object to which it points), humans must constantly refer themselves to Being, and, in this way, they must reinforce their essential separation from it. In other words, like any sign, humans receive their meaning only by virtue of their separation from their signifier-Being. We are a sign that is not read.

Of Hölderlin's statement, however, what is even less clear is what might read this "human sign", and how it is be done. Heidegger, in discussing the movement of Being as either drawing toward, or away from, human beings, appears to suggest that to 'read' a sign is to engage with it on a fundamental level. Heidegger invites this broad interpretation of the word "read," as he refers to a sign beyond an image or a written word, such as items of thought or beings who "point" in their relation to Being. For one to read a sign like a road sign — that is one thing. To read a sign that is a human being pointing toward Being in its essential nature-that is another. Heidegger recognizes the complexity of the task at hand and offers some clarifying words, in which he provides the withdrawal of Being and its existence beyond the scope of our language as justifications for why we are not read. He writes: "When man is drawing into what withdraws, he points into what withdraws. As we are drawing that way we are a sign, a pointer. But we are pointing then at something which has not, not yet, been transposed into the language of our speech. We are a sign that is not read". ${ }^{3}$ Here it seems that Heidegger believes that for a sign to be read, it must point to a thing that, in turn, meets it and coexists with it on some level of existence. The semantic correspondence between the word or idea of a tree and the actual tree itself creates meaning for the sign. Yet, if the tree were to reject definition,

2 Heidegger, Martin. "What Is Called Thinking?, trans." J. Glenn Gray (New York: Perennial Library, 2004), 149. 3 Ibid., 18. 
or otherwise escape human understanding, the sign would not be read. We draw into what withdraws, and escape the language of our speech. As such, we are a sign that is not read.

This withdrawal, however, is by no means permanent - the idea that we are a sign presupposes the possibility of our pointing's eventually reaching the thing to which we aspire. Heidegger acknowledges this in his inclusion of the words "not yet" when describing how Being has eluded our faculty of language. Set off by commas, the phrase is, rhetorically, something of a side note to the idea that what we draw toward withdraws from us. The phrase is hopeful. Heidegger believes in humanity's ability to reach Being, and to receive meaning from the thing that gives us our essence, insofar as we point toward it. Indeed, he reinforces this hope through his constant assurances that we are still not thinking, rather than just not thinking. Heidegger also does not think that our inability to reach Being is entirely our fault either, stating, "that we are still not thinking is by no means only because man does not yet turn sufficiently toward that which, by origin and innately, wants to be thought about since in its essence it remains what must be thought about. Rather, that we are still not thinking stems from the fact that the thing itself that must be thought about turns away from man, has turned away long ago." 4 This idea reinforces the dual aspect of our search to find Being, as it requires a bidirectional relationship: as humans point toward Being, so too must Being point toward us. Heidegger could build on Hölderlin's verse, in saying that we are a sign that is still not read, even though, perhaps, we once were.

The temporariness of this uniquely human condition-that we still have not met Being in such a way that allows us to be read-is in no small part due to language's having prevented humans from engaging, on an essential level, with Being. For although the human being as a pointer makes him similar to the linguistic sign, a relation to Being requires a more fundamental engagement, which cannot be hindered by the constrictions set in place by language. Heidegger is deeply troubled by the completeness and finality of meaning that language purports to provide, and throughout What Is Called Thinking?, strives to redefine ordinary words and lines from other writers. Nonetheless, this unusual process of translation, for Heidegger, is only getting to the true meanings of words (or moving closer to their relationship with Being), as language is, itself, a collection of bungled signs. Heidegger writes: "It is not we who play with words, but the nature of language plays with us, not only in this case, not only now, but long since and always. It is as though man had to make an effort to live properly with language. It is as though such a dwelling were especially prone to succumb to the danger of commonness". ${ }^{5}$ This commonness, and this dwelling, are what prevent humanity and Being from fully aligning. We live inside language, and therefore, cannot interact with aspects of the world that go beyond its scope. In the spirit of Heidegger, Hölderlin's line may become: We point

4 Ibid., 6-7.

5 Ibid., 118-119. 
but are waiting for that metaphysical principle to which we point to point back to us. We are waiting for Being to meet us where we are. For it do so, we must allow it to. By redefining our relationship to Being, we are freeing ourselves to more directly seek Being, and vice versa.

Up until now, we have discussed pointing as a form of striving, which implies that signs are in some way not partaking in Being, but are, rather, outside of it. According to Heidegger, signs, being permitted to partake in a relationship with their signifier, can become conjoined with the essence of their signifier, and, in that way, they become as necessary a part of its existence as anything. Heidegger's description of the characteristics of language can be applied to humans, as they relate to Being: "Language admits of two things: One, that it be reduced to a mere system of signs, uniformly available to everybody, and in this form be enforced as binding; and two, that language at one great moment says one unique thing, for one time only, which remains inexhaustible because it is always originary, and thus beyond the reach of any kind of leveling". ${ }^{6}$ By signs' being "uniformly available to everybody," Heidegger seems to say that they contain no original reality, which, in its specificity, could render the sign inaccessible or unreadable to anyone. As such, the sign is binding-in other words, it receives its essence from its signifier. For humans, this would mean that our pointing toward being binds us with it in an essential way. The crux of the second characteristic is perhaps even more obscure, but an understanding of it may be found in the word "originary," which can mean "primitive" or "productive." In the sense of "primitive," language may be originary in that it originated long ago in humans - at the same time that Heidegger says Being turned away from us. Heidegger may also be saying that language is productive, yielding new meaning with each utterance. Yet, while any combination of signs can yield new meaning, there can be only one relationship of sign to signifier. Language as a combination of signs is constantly productive, but the relation of sign to signifier, or of human to Being, is transcendent, in that it is fixed in its singular meaning.

Given this discussion of language, we may be in some position to examine the two lines that directly succeed our aforementioned line from Hölderlin's poem: "We feel no pain, we almost have/ Lost our tongue in foreign lands". ${ }^{7}$ In Hölderlin's words, we seem to be in the realm of language. The verse mentions losing one's tongue-a reference to shedding the constraints of language, and, as a result, feeling no pain (i.e., being transcendent). In that way, the passage describes our search for Being. The word "almost" weighs heavily on the pair of lines, as it refers to humanity's asymptotic approach towards Being - a necessary characteristic of which being humans' withdrawnness from Being. Heidegger does not explicate these lines for us, which raises questions about why he chose to include them. But while they could be read as describing transcendence, they are more likely to be referring to

6 Ibid, 191-192.

7 Ibid., 10. 
humanity's conundrum of not being able to relate properly to Being. Indeed, the lines are indicative of a sense of alienation that accompanies the sign that "stays without interpretation". ${ }^{8}$ That we are in "foreign lands" reflects the unreciprocated relationship between humanity and Being. One might read the phrase "our tongue" not literally as "language," but rather as some essential characteristic of our being that is lost, having been corrupted by the "dwelling" in which we have had to make an effort to live. Language is likely to be the "foreign lands" to which Heidegger refers, as it is clear that he does not think of language as something that comes naturally to humans. The "tongue" that Hölderlin speaks of, at least for Heidegger, is something much more essential and closely tied to Being than language is. Heidegger warns against succumbing to the commonness of language, making this more broad interpretation of the word "tongue" a more consistent way of thinking about how he might view these lines. As we remain without interpretation, we remain separated from that in which we may be at home-Being.

In subsequent lines of his discussion of the poem, Heidegger derives great meaning from one of its various titles, "Mnemosyne," which is the name of a Titaness in an ancient Greek myth. Heidegger's view of the poem's character as myth-like is a form of reflecting on the nature of myth-telling. "Myth means the telling word," he writes. "For the Greeks, to tell is to lay bare and make appear-both the appearance and that which has its essence in the appearance, its epiphany." It would seem initially that telling as "laying bare" contradicts what we have said before about language as obfuscating. Laying bare means to expose, reveal, uncover. But telling is not only laying bare-it is also making appear, which is distinct from exposure in that the latter refers to what has always been there, or at least once was and now is again. Given that Being turned away from us long ago, it remains that thing which, for Heidegger, is most important to expose, or to acquire anew. By turning toward Being, we call it to appear to us - to reveal itself to us. We want it to point back to us. Being has its essence in this epiphany, which occurs through pointing. For the Greeks, telling is the thing that exposes Being: "The mythos is that appeal of foremost and radical concern to all human beings which makes man think of what appears, what is in being". ${ }^{10}$ The act of telling implies a listener-a relationship. The exposure comes in the act of telling: telling is the mark of a sign that reaches for a signifier.

To describe more accurately the relationship between language and telling, Heidegger employs the terminology of lying and letting lie, which, in turn, gives us new latitude to think about the ways in which we point to Being. We have thus drawn a distinction between language, which confuses our search for Being, and telling, which is an act that uses language to connect otherwise discrete elements. Telling, or stating, is parallel to the pointing-towards done by the sign, which Heidegger 
says we are. For Heidegger, language is something that we bring into the world by uncovering it and letting it lie: "The essential nature of stating is not determined by the phonetic character of words as signs. The essential nature of language is illumined by the relatedness of what lies there before us to this letting-lie-before-us". ${ }^{11}$ When we use language — when we employ it through stating or telling — we allow it to lie before us. It is in front of us, and we point towards it. It is with Being. The essential nature of humanity's relation to Being may be summarized in the exact same terms that Heidegger uses to characterize the essential nature of language. When we point toward Being, we attempt to let it lie before us. But as it has turned away from us, it cannot lie before us, and rather lies outside of our grasp.

A key question raised by the notion of lying and letting lie is how it applies to signs, and the interpretation of the sign by its signifier, such that it may be read. Heidegger says that the letting lie of Being is that essential trait that characterizes our experience:

When man finds himself among what so lies before him, should he not respond to it in all purity by letting it lie before him just as it lies? And this letting-lie, would it not be that laying which is the stage for all the other laying that man performs? Thus laying would now suddenly emerge as a relatedness that pervades man's stay on this earth from the ground upthough we have never asked where this relatedness originates. ${ }^{12}$

The notion of origin emerges once more: similarly to Heidegger's description of language as originary, here the philosopher says that laying is something also originary, in that it must always be a characteristic of existence. Humanity has always responded to the laying by letting-lie, which has constituted our attempts at relating to Being. These have been successful attempts, as Being, which withdraws, allows for something concrete that humanity can let lie. This is the act of withdrawal. But as we let Being's withdrawal lie before us, Being does not turn to meet us, as would be necessary for a meaningful encounter. The relationship carries on one-sidedly, as it has since the beginning.

In a way, by reproducing Hölderlin's words and by letting them lie on the page before the reader, Heidegger is placing us on the path toward Being by uncovering the truth of Hölderlin's words. We should have no confusion about what the poem is. The poem is language! Its truth, therefore, should be muddled by that dwelling in which we live, which is essentially separate from our more fundamental relation to Being. Its words, however, point toward truth in the way that we point toward truth, and, as a result, show us along the path toward Being: "Its statement rests on its own truth. This truth is called Beauty. Beauty is a fateful gift of the essence of truth, and here truth means the disclosure of what keeps itself concealed" ${ }^{13}$ Heidegger believes

11 Ibid., 202.

12 Ibid., 206.

13 Ibid., 19. 
that the disclosure of what keeps itself concealed — that is, Being-is what provides its actuality and gives meaning and interpretation to that which seeks it. The sign is vindicated by the laying-bare of its signifier. Similarly, the line, "We are a sign that is not read," is itself a sign, which rests on its truth, in that it makes apparent the thing to which it points. We follow these pointers toward truth and Being, Heidegger says, and the alienation from Being experienced by humanity comes as a result of being separated from this truth-the truth that Being has taken with it in its withdrawal from us. Being is, most fundamentally, the thing that does not make itself apparent to us. Our greatest concern with it is that it is hidden-that it has turned away. Somehow, Heidegger says, this poem has used language to demonstrate its truth. But demonstrate is not exactly the correct word. He says that the poem "rests" on its truth, which does not imply laying-bare, but rather being hidden below the surface, as a house rests on a foundation that is underground. The language is a sign that points toward the truth.

Heidegger urges us to take this leap from language to truth — sign to signifier — in our search for Being, as we point toward it and struggle to access it: "Why this reference to language? In order to stress once again that we are moving within language, which means moving on shifting ground or, still better, on the billowing waters of an ocean". ${ }^{14}$ The entire project of a sign is to transcend its order, to point toward something more actual than itself, and to have that thing meet it to create meaning. When we look for Being, Heidegger says, we are leaping out of something-in this case, language - and are landing on something that gives us our essential nature. We leap out of everything pertaining to our foreign linguistic dwelling, and we meet Being so that it may meet us: "For that is what we are now, men who have leapt out of the familiar realm of science and even, as we shall see, out of the realm of philosophy. And where have we leapt? Perhaps into an abyss? No! Rather, onto some firm soil". ${ }^{15}$ In understanding the nature and limits of language, we can hope to escape it. Only then can we find Being, resting upon its "firm soil," and only then can Being find us.

\section{BIBLIOGRAPHY}

Heidegger, Martin. What Is Called Thinking?'Trans. J. Glenn Gray. New York: Perennial Library, 2004.

14 Ibid., 192.

15 Ibid., 41. 